\title{
МЕТОДИЧЕСКИЕ ПОДХОДЫ РАЗРАБОТКИ МОДЕЛИ АНАЛИЗА ОПТИМИЗАЦИИ СТРУКТУРЫ КАПИТАЛА КОМПАНИЙ
}

\author{
(c) 2019 Лысенко Юлия Валентиновна \\ доктор экономических наук, доцент, профессор \\ Финансовый университет при Правительстве Российской Федерации, Россия, Челябинск \\ E-mail: lysenkoyulia@mail.ru \\ (c) 2019 Якушев Анатолий Алексеевич \\ кандидат технических наук, доцент, профессор \\ Финансовый университет при Правительстве Российской Федерации, Россия, Челябинск \\ E-mail: su-7@mail.ru
}

(c) 2019 Лысенко Максим Валентинович

доктор экономических наук, профессор

Южно-Уральский государственный гуманитарно-педагогический университет, Россия, Челябинск

E-mail: dec_eib@mail.ru

(c) 2019 Белоконов Юрий Владимирович

старший преподаватель

Южно-Уральский государственный гуманитарно-педагогический университет, Россия, Челябинск

E-mail: superbest@inbox.ru

В данной статье рассмотрены методические подходы к разработке модели анализа оптимизации структуры капитала компании, которая сосредоточена на концепции, включающей в себя подход результативного использования капитала, его рентабельность; подход результативного использования заемного капитала; подход сбалансированности источников обеспечения деятельности предприятия.

Ключевые слова: модель, эффективность, финансовая устойчивость, концепция, леверидж, рентабельность, капитал, капиталоёмкость, прибыль, оптимизация.

Модели анализа оптимизации структуры капитала являются популярным средством в финансовом менеджменте компаний.

В настоящей работе рассматривается модель анализа оптимизации структуры капитала в компании, построенная по основным принципам концепции.

Политика оптимизации структуры капитала предопределяет краткосрочную и долгосрочную финансовую стабильность компании, что позволяет классифицировать источники финансирования в соответствии с их приоритетом и стоимостью. Поэтому в зависимости от приоритета устанавливаются отношения с поставщиками, которые чаще всего являются акционерами и кредиторами. Акционеры предоставляют средства компании в форме собственного капитала, кредиторы - в виде кредитов, займов и кредиторской задолженности. Политика в области управления структурой капитала (Higgins, R.L., 2003), (Tsolakis, N.K., 2014), рассмотренная в ис- следовании, направлена на поиск наиболее выгодной структуры собственного и заемного капитала в общей его совокупности, соотношения между собственными и заемными средствами.

Точного значения структуры капитала, которая является оптимальной, не выявлено до сих пор, несмотря на большое количество исследований в этой сфере О.А. Герасименко, В.И. Молокова (Герасименко, Молокова, 2017, с. 154-157), Л. В. Давыдова, С.А. Ильминская (Давыдова, Ильминская, 2015, с. 42-51), Ю.В. Кириллов, Е.Н. Назимко (Кириллов, Назимко, 2014, 2015, с. 57-63, 55-65), М.И. Лисица (Лисица, 2014, с. 48-55), Р.М. Нуреев (Нуреев, 2014, с. 562) А.Е. Пиняева (Пиняева, 2016, с. 16), Н.Б. Рудык (Рудык, 2014, c. 272).

Причиной этого являются экономические, социальные, политические условия, которые действуют в разных странах. Но большое внимание при этом должно быть уделено отраслевым характеристикам, жизненному циклу компании, 
рентабельности ее деятельности, а также макроэкономическим циклам. Эти факторы образуют уникальную комбинацию, в которой оптимальное значение кредитного плеча является чаще всего индивидуальным для каждой отдельно взятой компании. И.А. Бланк (Бланк, 2015, 512 с.), В.В. Бочаров (Бочаров, 2014, с. 289), В.В. Ковалев (Ковалев, 2015, с. 768), Л.Р. Хабибуллина, А.В. Янгиров (Хабибуллина, Янгиров, 2017, с. 3339), (Baidakov A. etc., 2015), (Fritz M., Schiefer G., 2008).

Во всех упомянутых работах представлены подходы разных ученых к содержанию понятия «капитал» (Руденко, 2014, с. 35-58), (Русанова, 2015, с. 44-53), (Хлебникова, Рахимов, 2015, с. 152-156), (Чараева, 2015, с. 11-17), (Хабибуллина, Янгиров, 2017, с. 33-39); (Бланк, 2015, с. 512); (Бочаров, 2014, с. 289).

Основное внимание этих работ сосредоточено на принципах Концепции оптимизации структуры капитала производственной компании, которые включают в себя следующие:

1) метод результативного использования капитала. Представленный метод подразумевает высокую степень прибыльности капитала, капитализацию чистой прибыли в экономическом развитии компании. Для производственных компаний наиболее важной является величина доли перераспределения капитала в активах. При определении прибыльности капитала следует иметь в виду, что от чистой прибыль уплачиваются дивиденды собственникам, поэтому заложенного уровня чистой рентабельности должно быть достаточно как для выплаты дивидендов, так и для роста собственного капитала компании за счет капитализации части чистой прибыли;

2) метод результативного использования заемного капитала. Рассматриваемый метод подразумевает высокую степень прибыльности заемного капитала. При построении предприятием политики ценообразования, прогнозирования степени прибыльности, привлекая заемные средства посредством банковских кредитов, необходимо также обращать внимание на величину расходов на обслуживание полученных кредитов. Степень прибыльности заемного капитала не должна быть ниже процентной ставки по приобретенному кредиту;

3) метод результативности и экономного использования материальных и финансовых ресурсов организации;
4) метод сбалансированности источников обеспечения деятельности организации;

5) метод увеличения привлекательности компании для инвесторов.

Реализация Концепции можно выполнить посредством проведения исследования совокупного капитала производственной компании. Для этого авторами разработана модель анализа капитала компании. При этом анализ был разделен на следующие этапы:

1) горизонтальный и вертикальный анализ капитала компании;

2) исследование финансовой устойчивости компании;

3) исследование результативности и интенсивности использования капитала;

4) анализ факторов прибыльности совокупного капитала.

Для оптимизации структуры капитала был проведен анализ по следующим этапам.

Первый этап - исследование изменения и величины доли совокупного капитала компании. Подразумевает осуществление исследования динамики величины собственного и заемного капиталов в качестве главных источников обеспечения деятельности. Исследование изменения осуществляется способами горизонтального анализа и предполагает определение абсолютного и относительного отклонения или изменение величины собственного и заемного капитала в рассматриваемом году по сравнению с прошлым годом. Исследование величины доли капитала проводится способом вертикального анализа и дает возможность оценить величину долю собственного и заемного капиталов в совокупной величине источников обеспечения деятельности компании.

Второй этап - исследование финансовой устойчивости компании. Данный анализ дает возможность определить степень зависимости компании от заемных источников обеспечения деятельности. Для этого производится абсолютное и относительное изменение финансовой устойчивости. Абсолютное изменение предполагает определение степени вероятности компании финансировать оборотные активы в части запасов посредством собственного капитала и образовывать собственный оборотный капитал (СОC).

Источники формирования запасов представлены в работах ученых - экономистов Л.С. Шохина, О.В. Брыкина (Шохина, Брыкина, 
2017, с. 26-33), И.И. Просвирина, В.В. Проскурина (Просвирина, Проскурина, 2016, с. 3), которые были учтены при разработке модели анализа оптимизации структуры капитала компании.

В зависимости от того, положительное или отрицательное значение получилось по СОС, СД (собственные и долгосрочные источники) и ОИ (общая величина основных источников), определялся тип финансовой устойчивости: абсолютная; нормальная; неустойчивое; кризисное финансовое положение (Borodin V. etc., 2016, Bochtis D. etc., 2014).

Третий этап - исследование результативности и интенсивности использования капитала. На данном этапе анализируется эффективность и интенсивность использования капитала в целом и его отдельных элементов (в структуре собственного капитала и обязательств).

Эффективность использования капитала характеризуется его доходностью (рентабельностью). В процессе проведения анализа эффективности анализируется динамика изменения таких показателей, как:

1) коэффициент рентабельности всего используемого капитала. Этот же показатель называют рентабельностью активов (ROA);

2) коэффициент прибыльности собственного капитала;

3) коэффициент прибыльности заемного капитала.

Для исследования интенсивности использования капитала рассчитывался коэффициент оборачиваемости общего капитала и время одного оборота. Так, коэффициент оборачиваемости общего капитала (или капиталоотдача) показывал скорость оборота всех источников финансирования деятельности компании.

Взаимосвязь между показателями рентабельности совокупного капитала и капиталоотдачей выражалась следующим образом:

$$
\frac{\Pi_{\text {чИС }}}{K_{C P}}=\frac{\Pi_{\Pi P}}{B_{P \Pi}} \times \frac{B_{P \Pi}}{K_{C P}},
$$

или

$$
R O A=K_{O Б} \times R_{I P} .
$$

Четвертый этап - факторный анализ рентабельности совокупного капитала.

Расчет влияния факторов первого порядка на изменение уровня рентабельности совокупного капитала производился методом абсолют- ных разниц:

$$
\begin{aligned}
& \triangle R O A_{K_{O Б}}=\Delta K_{O Б} \times R_{I P P}, \\
& \Delta R O A_{R_{I P}}=K_{O Б 1} \times \Delta R_{I P P} .
\end{aligned}
$$

Целью настоящей работы является изложение методического подхода к разработке модели анализа оптимизации структуры капитала компании. В качестве меры зависимости используется факторный анализ рентабельности совокупного капитала. Показано, что факторная модель учитывает различные методические подходы к разработке оценки структуры источников финансирования деятельности компании, эффективности использования собственного и заемного капитала, разработке управленческих решений, которые подразумевают оптимизацию структуры капитала посредством увеличения капиталоотдачи. Это позволяет рекомендовать указанные процедуры для практического применения.

Актуальной, таким образом, становится задача построения модели анализа оптимизации структуры капитала компании и оптимизация левериджа.

Оптимизация структуры капитала будет базироваться на следующих этапах:

Этап 1. Анализ структуры и источников капитала производственной компании.

На первом этапе проводится анализ структуры и источников капитала. Основной целью анализа при этом остается диагностика тенденций изменения величины объема и элементов капитала в отчетном периоде, их влияние на устойчивость компании и эффективность использования капитала.

Ниже показано, что данный вывод справедлив для производственных компаний.

Этап 2. Исследование главных факторов, оказывающих значительное влияние на определение структуры капитала.

На втором этапе проводится исследование главных факторов, оказывающих значительное влияние на определение структуры капитала. Имеется ряд показателей, учет которых благоприятствует целевому определению структуры капитала, при этом гарантируя тенденции максимально результативного его использования на каждой конкретной компании.

В состав факторов, влияющих на формирование структуры капитала компании, оценка 
влияния которых проводится во время второго этапа процесса оптимизации, можно включить следующие:

- стадия жизненного цикла компании. На начальных стадиях своего развития производственные компании могут пользоваться заемным капиталом при условии выпуска или реализации конкурентоспособной продукции, при этом стоимость кредитных ресурсов может быть достаточно высокой, так как высоки финансовые риски. В то же время компании, находящиеся на стадии зрелости, должны работать максимально на использовании собственного капитала;

- отраслевые особенности хозяйственной деятельности производственной компании, характер, определяющий структуру активов компании и уровень их ликвидности;

- спрос и предложение на товарном рынке. Чем стабильнее конъюнктура рынка на реализуемую продукцию, тем ниже риск использования заемного капитала. И, наоборот, в условиях неблагоприятной конъюнктуры рынка и снижения объемов продаж эксплуатация заемного капитала может привести к значительному уменьшению чистой прибыли и появлению риска потери платежеспособности компании. Поэтому возникает необходимость уменьшать показатель финансового левериджа посредством снижения величины кредитных средств;

- конъюнктура финансового рынка, в зависимости от которой увеличивается или уменьшается величина заемного капитала;

- Степень прибыльности основной деятельности компании. От величины коэффициента напрямую зависит рейтинг кредитоспособности производственной компании, увеличивает резервы возможного использования заемного капитала;

- уровень ставок налога на прибыль. Чем ниже ставки налога или имеются возможности применения налоговых льгот, тем выше уровень капитализации чистой прибыли в деятельность;

- уровень концентрации собственного капитала.

Этап 3. Улучшение структуры капитала через фактор увеличения до наибольшего уровня финансовой прибыльности.

На третьем этапе используется показатель финансового левериджа с целью улучшения структуры капитала через фактор увеличения до наибольшего уровня финансовой прибыльности. Этот механизм дает возможность эффективно управлять прибыльность капитала компании посредством улучшения структуры капитала производственной компании.

Этап 4. Определение наилучшей структуры капитала по методу максимального снижения его стоимости.

На четвертом этапе осуществляется определение наилучшей структуры капитала по методу максимального уменьшения его величины. Данное улучшение основывается на предварительное исследование величины совокупного капитала в случае различных условий его привлечения и использования многочисленных расчетов средневзвешенной величины капитала.

Этап 5. Оптимизация структуры капитала по критерию минимизации уровня финансовых рисков.

На пятом этапе проводится улучшение структуры капитала посредством метода минимизации степени финансовых рисков.

Этап 6. Определение критериев структуры капитала по целевой направленности.

На шестом этапе формируются показатели структуры капитала по целевой направленности.

Стоит отметить, что не существует единых инструкций оптимального соотношения заемного и собственного капитала. При выборе наилучшего источника обеспечения экономически целесообразно исследовать как количественные, так и качественные параметры доступности ресурсов, а также необходимо осуществить качественное и количественное исследование каналов обеспечения для определения уровня их надежности.

Апробацию модели анализа оптимизации структуры капитала проводили на конкретных производственных компаниях. Для этого информационную основу оценки составляли по данным бухгалтерской (финансовой) отчетности.

На основе проведенных исследований было установлено, что не выполняется нормативное значение коэффициента обеспеченности собственными средствами от 0,1. Полученные результаты - 0,02 в 2014 году, 0,04 в 2015 году и 0,06 в 2016 году.

Аналогичная ситуация с коэффициентом обеспеченности запасов собственными средствами, при норме от 1,0 результат в 2014 году 0,16, в 2015 году - 0,15 и в 2016 году - 0,16.

Значение коэффициента финансовой независимости свидетельствует об очень низкой 
доле собственного капитала в общей структуре источников финансирования $(0,02$ в 2014 году, 0,05 в 2015 году и 0,11 в 2016 году), хотя динамика положительная.

Наблюдается отрицательная динамика по результатам расчета коэффициента маневренности с 1,00 в 2014 году до 0,51 в 2016 году, то есть снижается обеспеченность собственными оборотными средствами.

Результаты расчета коэффициента финансового левериджа показывают, что заемный капитал превышает собственный в 43 раза в 2014 году, в 19 раз в 2015 году и в 8 раз в 2016 году, то есть повышается финансовая устойчивость производственной компании за период 20142016 гг. за счет капитализации чистой прибыли в деятельность в 2015-2016 гг.

Положительные изменения в уровне финансовой устойчивости также характеризуют результаты расчета коэффициента долгосрочной финансовой независимости. Несмотря на невысокие значения этого коэффициента в 20142016 гг., плюсом является положительная динамика с 0,02 до 0,11.

Таким образом, производственной компании необходимо продолжить курс на повышение капитала компании посредством капитализации чистой прибыли по результатам деятельности в каждом отчетном периоде на перспективу. При этом если в 2014-2015 гг. наблюдается существенный рост обязательств (кредиторской задолженности), то в 2015-2016 гг. эти обязательства немного сократились, хотя доля заемного капитала в его общей структуре по-прежнему высока - 89\% на конец 2016 года.

Также необходимо отметить, что низкая степень прибыльности продукции и продаж. Производственной компании необходимо обязательно акцентировать внимание на данной тенденции и придерживаться при определении стратегии будущего развития на увеличение чистой прибыли, притока чистой прибыли и ее капитализации в деятельность компании, что будет способствовать наращению собственного капитала компании и её финансовой независимости.

В этом разделе показана финансовая устойчивость производственной компании, построенная на основе модели анализа оптимизации структур капитала. Для этого нами была составлена схема доказательств практического применения модели.
При апробации модели мы рекомендовали компаниям прибыль направить в развитие их деятельности и наращивание финансовых результатов. Это будет способствовать росту капитала и повышению его доли в общей структуре источников финансирования производственной деятельности.

Оценку изменения рентабельности деятельности производственной компании, а также структуры источников финансирования их деятельности мы проводили в конкретный период. За счет чистой прибыли, капитализированной в производственную деятельность в данный период производственной компании, ожидается повышение удельного веса собственного капитала в общей структуре источников финансирования её деятельности. Расчет коэффициентов рентабельности и структуры источников представлен в табл. 1. Данные, представленные в таблице 1 , показывают, что удельный вес собственного капитала в общей структуре источников финансирования повысится за счет чистой прибыли компании.

На основе регрессионного анализа провели прогнозирование показателей рентабельности деятельности производственной компании и определили уравнение регрессии, выполняя соответствующие расчеты в программе «Statistica 6.0», используя статистические функции. Результаты анализа представим в табл. 2.

Структура капитала производственной компании после реализации изменится следующим образом: доля собственного капитала повысится с $11,17 \%$ в 2016 году до 19,69\% в 2018 году, доля заемного капитала снизится с 88,83\% в 2016 году до 80,31\% в 2018 году (рис. 1).

Уровень рентабельности совокупного, собственного и заемного капитала производственной компании в плановом периоде повысится.

Так, на рис. 2 представлено изменение рентабельности собственного капитала производственной компании, которая повысится с 75,65\% в 2016 году до 170,60\% в плане.

Такой значительный рост связан с тем, что сумма чистой прибыли будет значительной, но, возможно, прочие расходы компании снизятся. Кроме того, за счет капитализации чистой прибыли повысится размер собственного капитала.

На рис. 3 представлены результаты изменения рентабельности заемного капитала, которая повысится с 6,59\% по факту 2016 года до 38,14\% в плане 2018 года. 
Таблица 1. Плановое изменение структуры источников финансирования, финансовой устойчивости и рентабельности капитала производственной компании

\begin{tabular}{|l|c|c|c|}
\hline \multicolumn{1}{|c|}{ Наименование показателя } & \multicolumn{3}{|c|}{ Значение показателя } \\
\cline { 2 - 4 } & 2016 год & план & $\begin{array}{c}\text { абсолютное } \\
\text { изменение }\end{array}$ \\
\hline 1. Выручка от продаж, тыс. руб. & 213546 & 531374 & 317828 \\
\hline 2. Себестоимость, тыс. руб. & 189128 & 443390 & 254262 \\
\hline 3. Прибыль чистая, тыс. руб. & 3743 & 56715 & 52972 \\
\hline 4. Капитал собственный, тыс. руб. & 6758 & 59730 & 52972 \\
\hline 5. Капитал заемный, тыс. руб. & 53723 & 243663,75 & 189940,75 \\
\hline 6. Доля собственного капитала,\% & 11,17 & 19,69 & 8,51 \\
\hline 7. Доля заемного капитала,\% & 88,83 & 80,31 & $-8,51$ \\
\hline 8. Коэффициент финансового левериджа (п.8/п.9) & 7,95 & 4,08 & $-3,87$ \\
\hline 9. Прибыльность совокупного капитала (активов) (RОА),\% & 6,06 & 31,07 & 25,01 \\
\hline Прибыль чистая, тыс. руб. & 3743 & 56715 & 52972 \\
\hline Стоимость совокупного капитала среднегодовая (активов), тыс. руб. & 61717,5 & 182555,6 & 120838,1 \\
\hline 10. Рентабельность собственного капитала,\% & 75,65 & 170,60 & 94,95 \\
\hline Чистая прибыль, тыс. руб. & 3743 & 56715 & 52972 \\
\hline Среднегодовая величина собственного капитала, тыс. руб. & 4948 & 33244 & 28296 \\
\hline 11. Прибыльность заемного капитала,\% & 6,59 & 38,14 & 31,55 \\
\hline Чистая прибыль, тыс. руб. & 3743 & 56715 & 52972 \\
\hline Среднегодовая величина заемного капитала, тыс. руб. & 56769,5 & 148693,4 & 91923,9 \\
\hline
\end{tabular}

Источник: расчеты авторов на основе данных Росстата.

Таблица 2. Результаты регрессионного анализа показателей рентабельности деятельности производственной компании

\begin{tabular}{|l|c|c|}
\hline \multicolumn{1}{|c|}{ Наименование показателя } & Уравнение регрессии & $\begin{array}{c}\text { Величина достоверности } \\
\text { аппроксимации }\left(\mathrm{R}^{3}\right)\end{array}$ \\
\hline Рентабельность совокупного капитала & $\mathrm{y}=0,022 \mathrm{x}+0,124$ & 0,311 \\
\hline Рентабельность собственного капитала & $\mathrm{y}=0,967 \mathrm{x}+0,899$ & 1,706 \\
\hline Рентабельность заемного капитала & $\mathrm{y}=0,028 \mathrm{x}+0,131$ & 0,381 \\
\hline
\end{tabular}

Источник: расчеты авторов на основе информации Росстата.

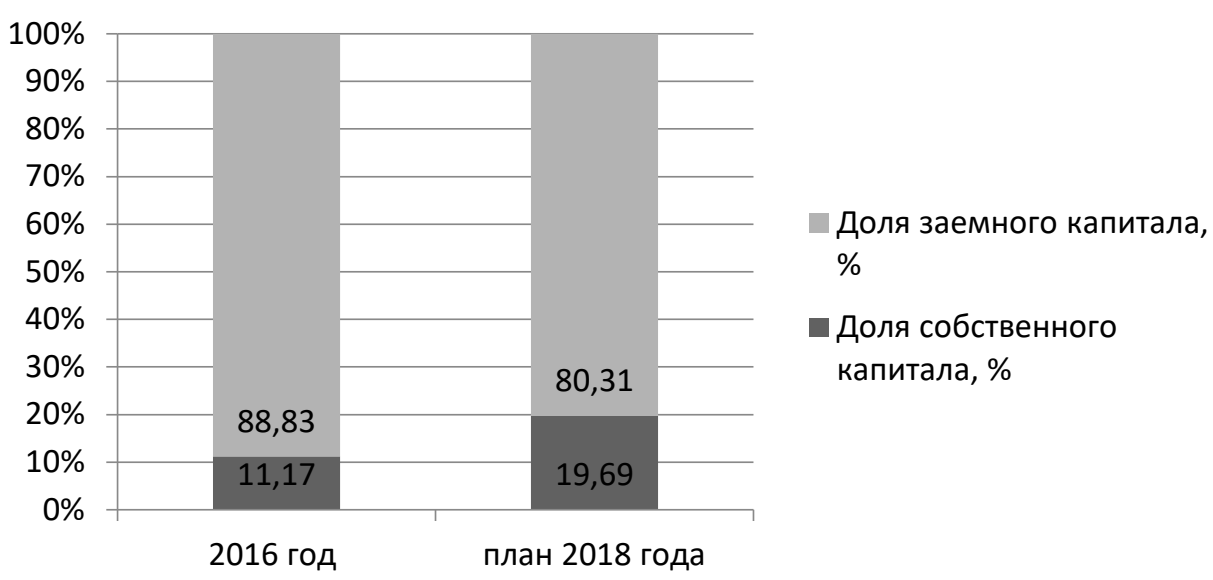

Puc. 1. Структура капитала производственной компании в плановом периоде Источник: составлено по данным Росстата 


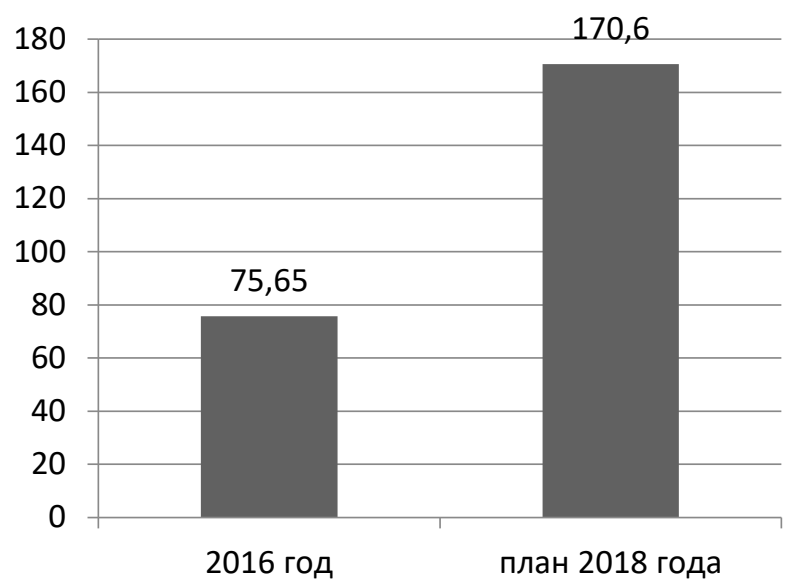

Рентабельность собственного капитала, \%

Puc. 2. Рентабельность собственного капитала производственной компании Источник: составлено по данным Росстата

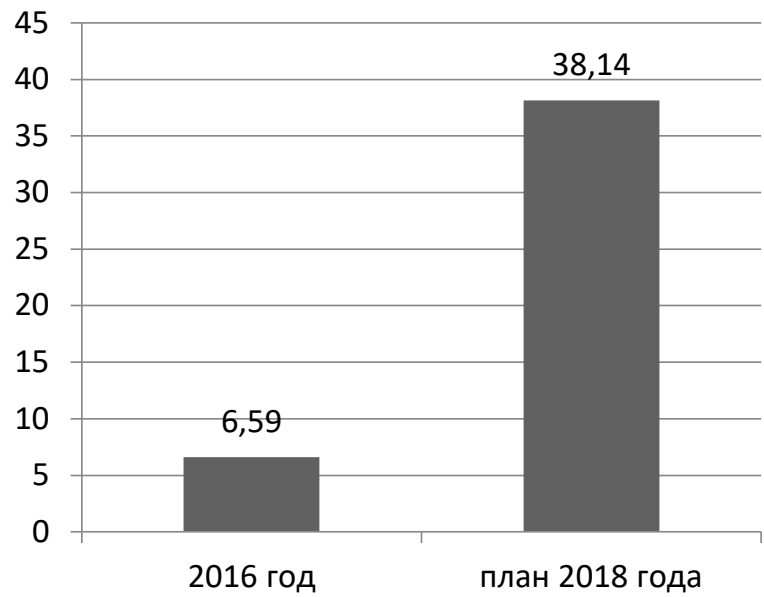

- Рентабельность заемного капитала, \%

Рuc. 3. Рентабельность заемного капитала производственной компании Источник: составлено по данным Росстата

Производственная деятельность не потребует дополнительных заемных средств в части банковского кредитования или кредитной линии. Но за счет отсрочки поставщиков сырья и материалов будет формироваться кредиторская задолженность (которая в настоящее время также является основным видом обязательств компании).

На рис. 4 представлено изменение рентабельности совокупного капитала производственной компании.

На рис. 5 представлено изменение всех показателей рентабельности. При этом плавно изменятся рентабельность совокупного капитала и заемного капитала, с большим рывком - рентабельность собственного капитала (только за счет того, что размер собственного капитала на конец 2016 года был очень небольшим, а чистая прибыль по производственной деятельности очень существенная).

Основным результатом настоящей работы является модель анализа оптимизации структуры капитала компании. Предлагаемая методология приводит к финансовой устойчивости компании на основе оптимизации структуры капитала. В основу методологии положена модель оптимизации структуры капитала, построенная по основным принципам концепции. Эта модель представляет самостоятельный интерес и имеет преимущества в использовании собственного и заемного капитала:

- простота процедуры привлечения; 


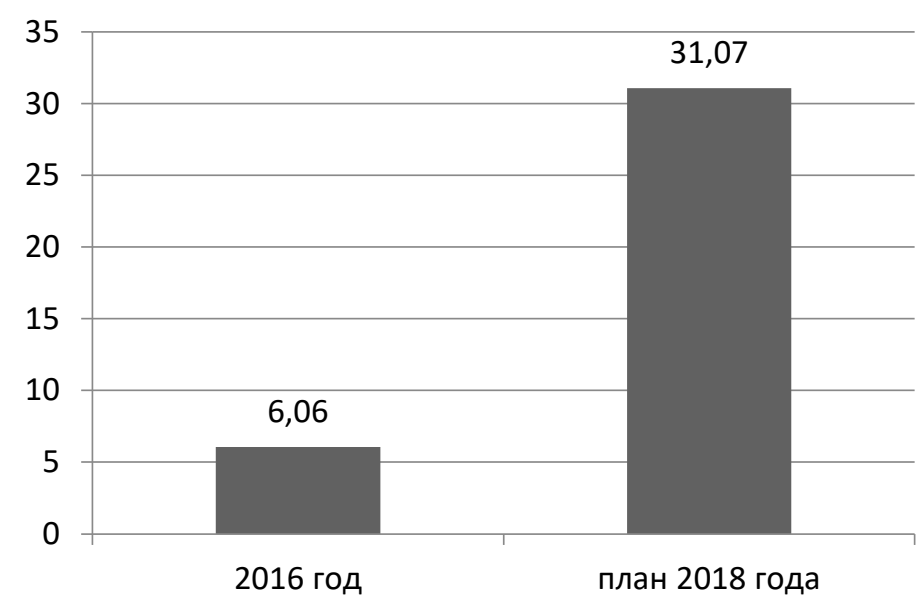

Рентабельность

совокупного капитала, \%

Puc. 4. Рентабельность совокупного капитала производственной компании Источник: составлено по данным Росстата

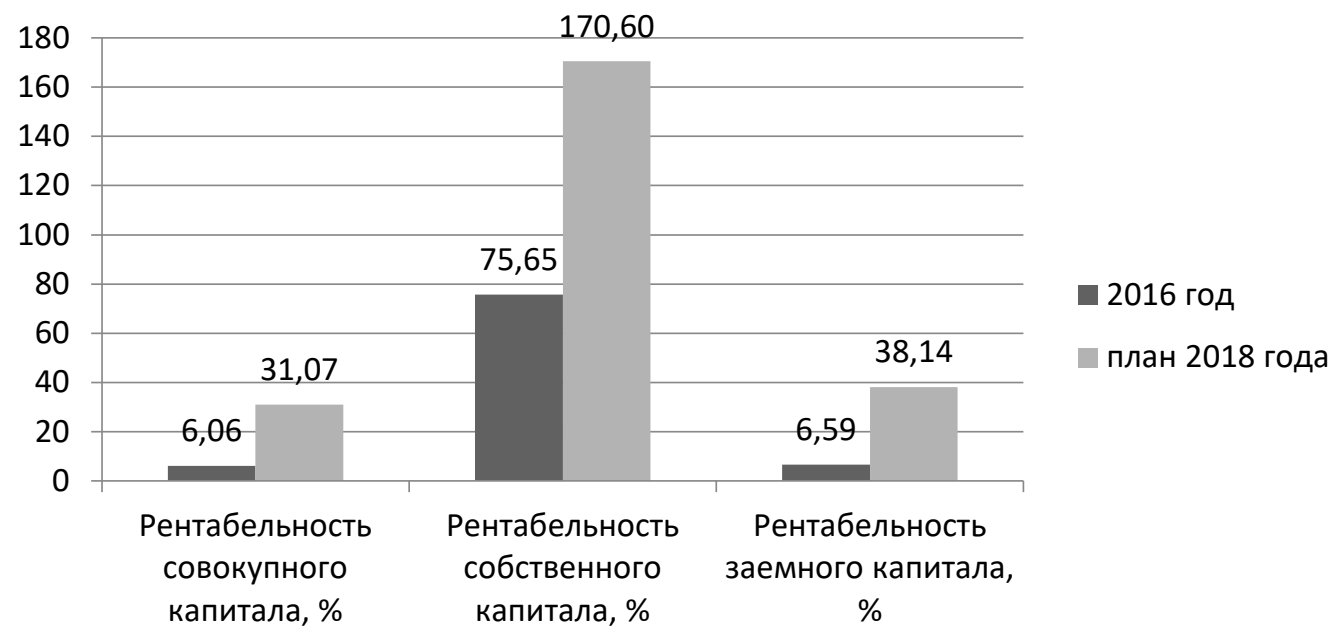

Puc. 5. Показатели рентабельности капитала производственной компании Источник: составлено по данным Росстата

- возможность капитализации чистой прибыли по итогам производственной деятельности за год и наращивания собственного капитала на этой основе;

- высокая доля собственных источников в структуре капитала положительно отражается на уровне финансовой устойчивости компании;

- возможность повышения стоимости финансового потенциала компании при необходимости увеличения ее активов и масштабов деятельности;

- способность обеспечивать рост прибыльности собственного капитала посредством эф- фекта финансового рычага;

- большие суммы заемных средств при наличии залога, поручительства;

- возможность включения расходов на обслуживание кредитного долга в себестоимость продукции, что позволяет снизить базу для расчета налога на прибыль.

Таким образом, предложенные в настоящей статье процедуры схем доказательств «финансовой устойчивости», построенных на основе модели анализа оптимизации структуры капитала для производственных компаний, могут быть рекомендованы для практического применения. 


\section{Библиографический список}

1. Бланк И.А. (2015). Основы финансового менеджмента // Ника-центр Эльга. С. 512

2. Бочаров В.В. (2014). Корпоративные финансы // Питер. С. 289

3. Герасименко О.А., Молокова В.И. (2017). Структура капитала и возможности ее оптимизации// Инновационная наука. Т. 1. № 3. С. 154-157

4. Губанова Е.В. (2017). Оптимизация структуры капитала организации // Вестник Воронежского института экономики и социального управления. № 1. С. 19-24

5. Губанова Е.В., Орловцева О.М. (2016). Многокритериальная оценка эффективности деятельности организации по данным бухгалтерской (финансовой) отчетности// Манускрипт. С. 80

6. Давыдова Л.В., Ильминская С.А. (2015). Особенности формирования структуры капитала предприятия// Финансы и кредит. № 47. С. 42-51

7. Кириллов Ю.В., Назимко Е.Н. (2014). Многокритериальная модель оптимизации структуры капитала// Экономический анализ: теория и практика. № 32. С. 57-63

8. Кириллов Ю.В., Назимко Е.Н. (2015) Решение многокритериальной задачи оптимизации структуры капитала// Экономический анализ: теория и практика. № 28 (331). С. 55-65.

9. Ковалев В.В. (2015). Введение в финансовый менеджмент// Финансы и статистика. № 32. С. 768

10. Кушнир И.В. (2010). Финансовый менеджмент// Финансы и статистика. 768 с.

11. Лисица М.И. (2014). Обзор моделей теории структуры капитала и анализ их состоятельности// Финансы и кредит. № 9. С. 48-55

12. Нуреев Р.М. (2014). Курс микроэкономики// ИНФРА-М. № 9. С. 562

13. Пиняева А.Е. (2016) Оптимизация структуры капитала предприятия // Политика, экономика и инновации. № 8 (10). С. 16.

14. Просвирина И.И., Проскурина В.В. (2016) Оптимизация капитала предприятия путем минимизации уровня финансовых рисков по данным бухгалтерской отчетности // Научно-аналитический экономический журнал. № 9 (10). С. 3.

15. Руденко A.M. (2014). Управление капиталом организации в условиях рынка// Финансы и кредит. № 43. C. 35-38

16. Русанова Е.Г. (2015). Теории структуры капитала: от источников до Модильяни и Миллера// Финансы и кредит. № 42. С. 44-53

17. Хабибуллина Л.Р., Янгиров А.В. (2017). Капитал предприятия и оптимизация его структуры // Научнопрактические исследования. № 1 (1). С. 33-39

18. Хлебникова Ю.В., Рахимов Т.Р. (2015). Оптимизация финансовой структуры капитала// Национальный исследовательский Томский политехнический университет. С. 152-156

19. Чараева М.В. (2015). Оптимизация структуры капитала при осуществлении инвестиционной деятельности организации// Финансы и кредит. С. 11-17.

20. Шохина Л.С., Брыкина О.В. (2017). Оптимизация структуры заемного капитала предприятия// Финансовый вестник. С. 26-33

21. Ahearn, M.A., Liang, K., Goetz, S. (2018). Farm business financial performance in local foods value chains. Agricultural Finance Review, doi: 10.1108/AFR-08-2017-0071.

22. Antle J., Basso B., Conant R., Charles H., Godfrayd J., Jonese J., Herrero M., Howittg R., Keating B., Munoz-Carpena R., Rosenzweig C., Tittonell P., Wheeler T. Towards a new generation of agricultural system data, models and knowledge products: Design and improvement (2017). AgriculturalSystems, 155: 255-268.

23. Bachev, H.A. Framework for Assessing Sustainability of Farming Enterprises (2016). Journal of Applied Economic Sciences, XI (1): 24-26.

24. Baidakov A., Chernobay N., Nazarenko A., Zaporozhets D., Sergienko E. Methodical Bases for Developing Predictive Scenarios of Agribusiness (2015). Asian Social Science, 11 (8), doi: 10.5539/ass.v11n8p9.

25. Becker G. S. Human Capital: A Theoretical and Empirical Analysis with Special Reference to Education. / New York, 1993. $-480 \mathrm{p}$.

26. Bochtis D., Claus G., Sørensen C., Busato P. (2014). Advances in agricultural machinery management: A review. Biosystems Engineering: 69-81, doi: 10.1016/j.biosystemseng.2014.07.012.

27. Borodin V., Bourtembourg J., Hnaien F., Labadie N. Handling uncertainty in agricultural supply chain management: A state of the art (2016). European Journal ofOperational Research, 254 (2): 348-359, doi: 10.1016/j.ejor.2016.03.057. 
28. Fountas S., Carli G., Sørensen C., Tsiropoulos Z., Cavalaris C., Vatsanidou A., Liakos B., Canavari M., Wiebens J., Tisserye B. Farm management information systems: Current situation and future perspectives (2015). Computers and Electronics in Agriculture, 115: 40-50. doi: 10.1016/j.compag.2015.05.011.

29. Fritz M., Schiefer G. Food chain management for sustainable food system development: a European research agenda (2008). Agribusiness, 24 (4): 440-452. doi: 10.1002/agr.20172

30. Hartarska, V., Nadolnyak, D., Shen, X., Agricultural credit and economic growth in rural areas (2015). AgriculturalFinanceReview, 75 (3): 302-312, doi 10.1108/AFR-04-2015-0018.

31. Higgins, R.L. (2003). Analysis for Financial Management.Seventh Edition-The McGraw-Hill Companies, 390 p.

32. Liwang Ma, Terry A Howell, Lajpat R. Ahuja. Agricultural System Models in Field Research and Technology Transfer. Retrieved April, 19, 2016 from https://www.taylorfrancis.com/books/9781420032413.

33. Plà, L., Sandars, D. \& Higgins, A. J. A perspective on operational research prospects for agriculture (2014). Journal of the Operational Research Society, 65 (7): 1078-1089, doi: 10.1057/jors.2013.45.

34. The electronic textbook on statistics StatSoft (2018). Retrieved March, 25, 2018, from http://www.StatSoft.ru/

35. Tsolakis, N.K., Keramydas C.A., Toka, A.K., Aidonis, D.A., Iakovou, E.T. Agrifood supply chain management: A comprehensive hierarchical decision-making framework and a critical taxonomy (2014). BiosystemsEngineering, 120: 47-64, doi: 10.1016/j.biosystemseng.2013.10.014. 